\title{
State of the art review: Strengthening of reinforced and pre-stressed concrete beams using externally bonded technique
}

\author{
M. A. ELSHIEKH ${ }^{1}$, M. A. Tayel ${ }^{2}$, and K. M. Heiza ${ }^{3}$ \\ 1. MS Candidate at Department of Civil Engineering, Faculty of Engineering, Menoufia \\ University, Egypt. \\ 2, 3. Professor of Reinforced Concrete Structures at Department of Civil Engineering, Faculty of \\ Engineering, Menoufia University, Egypt.
}

\begin{abstract}
Corrosion or other types of degradation caused by aging, etc. under environmental influences, poor routine maintenance leads to deterioration of concrete structures, which required repairing of these structures. In addition, structures, which needs to increase load carrying capacity because of changing usage, or considering some of design and construction defects due to poor quality control, must strengthened. So studying the effect of different methods of strengthening is very important. Using of fiber-reinforced polymers (FRP) is one of the more widely accepted methods for strengthening and repairing of reinforced concrete $(\mathrm{RC})$ and prestressed concrete structural elements. FRP had a number of benefit characteristic such as lightweight due to low density, easy handling, high strength, high stiffness and high corrosion resistance, which make it durability and require less maintenance.

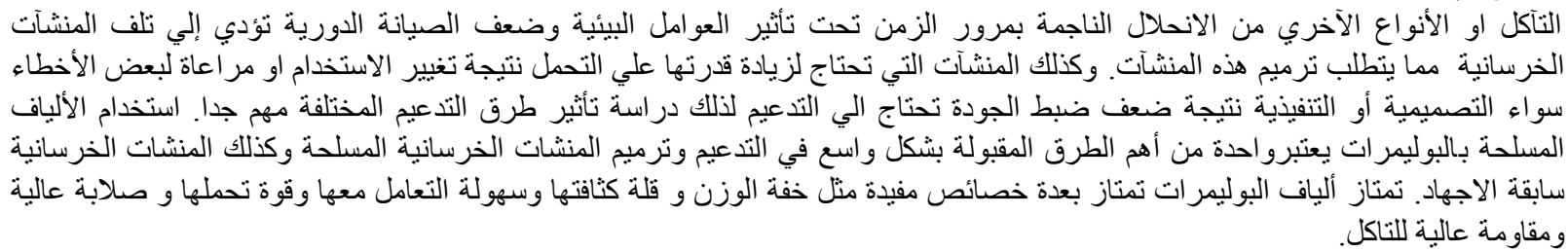

Keywords: Pre-stressed, reinforced concrete; Flexural strengthening; externally bonded; Fiber reinforced polymers; Failure modes.

\section{INTRODUCTION}

Strengthening of reinforced concrete, Structures mainly used to perform higher design loads, correct strength loss due to deterioration, correct construction or design defects, or increase ductility [1]. Flexural strengthening can be applied using externally bonded steel plates, steel or concrete jackets, external post-tensioning reinforcement and fiber-reinforced polymers (FRP). Generally, flexural strengthening with FRP divided into two methods: the nearsurface-mounted NSM and externally bonded EB systems [2][3]. There are three types of FRP: Carbon Fibers (CFRP), Glass Fibers (GFR), Aramid Fibers (AFRP) [4]. Externally bonded technique applied by roughen and cleaning the strengthening required surface, mixing adhesive components thoroughly then applying epoxy to the surface using brush and finally Placing of FRP laminates, there are many advantage of using FRP compared to using steel plates as performing high strength to weight ratio, resist environmental influences like corrosion, required less maintenance, easy to handled and more durability [5]. FRP Materials are brittle so the most common failure mode was FRP rupture, laminate debonding, and separation of concrete cover, and concrete crushing [6].

2. Advantages And Disadvantages Of (FRP) AND Steel As (EB) Strengthening Material

\subsection{Advantages of (FRP) AND STEEL AS (EB) STRENGTHENING MATERIAL}

Using of (FRP) composite materials has many benefits such as:
a) Lightweight.
b) Performed High Strength and stiffness to Weight ratio.
c) Resist environmental influences such as corrosion.
d) Easy to Shape, handle and transporting high workability.
e) Low heat conductivity.
f) More durability. 


\subsection{Disadvantages OF (FRP) Composites Material}

* FRP composites are brittle material (its failure is brittle not ductile).

* High manufacturing costs.

* Materials require refrigerated transport and storage and have limited shelf lives.

* Materials must be completely cleaned for all contamination before repair.

* Composites must be dried before repair because all resin matrices and some fibers absorb moisture.

* Repair at the original cure temperature requires tooling and pressure.

\section{STREngthening TechniQues USING FRP}

Generally, there are two methods for flexural strengthening with FRP composites: the first, externally bonded (EB) system and the second, near-surface mounted (NSM) system. NSM is a technique where the cover of concrete cut with certain dimensions to embed the steel bars or FRB rods in it using epoxy to make bond with concrete, some of the disadvantages of this method is difficult to be applied on existing structures, concrete cover separation. EB technique is easy to apply as the surface need to roughen and clean only before applying adhesive material and placing strengthening material. End inter facial delamination is one of the popular failure modes of EB FRP so using of wrapping is very important.

\section{Modes OF FAilure}

Different types of failure modes common at beams strengthened with FRP composites.

\section{a. FRP rupture:}

When stress at FRP laminate exceeds its tensile strength (usually at the maximum moment zone).

\section{b. Compression failure:}

When the max strain at concrete exceeds the ultimate strain capacity of concrete $(0.003)$ and the stress at reinforced steel is below the yield stress.

\section{c. Tension failure:}

The reinforcing steel in the tension zone begins to yield, resulting in large inelastic rotation of the beam. This results in eventual failure of concrete in compression zone, since steel could undergo large post yield strain and concrete fails just after reaching the ultimate strain.

\section{d. Shear failure:}

When the actual shear stress is greater than the shear capacity of the beam (at the section near the support).

\section{e. Deboning failure}

Occurs at three cases:

1. When interface shear stress between adhesive and concrete exceeds shear strength of the concreteadhesive interface.
2. When interface shear stress between the adhesive and FRP exceeds shear strength of the FRP adhesive interface.

3. When deponding begins at one of the flexural cracks and propagates towards the supports.

\section{e. Local shear-tension failure:}

A crack initially appear nearest the laminate end at the level of the tension steel reinforcement and propagates horizontally to mid-span.

\section{APPLICATIONS OF FRP FOR STRUCTURAL STRENGTHENING}

All over the world, FRP applied for a wide range of strengthening such as strengthening slabs using FRP strips, strengthening beams in shear and flexure, strengthening columns using FRP tubes and adhesive bonded FRP wraps as shown in Figure (1).

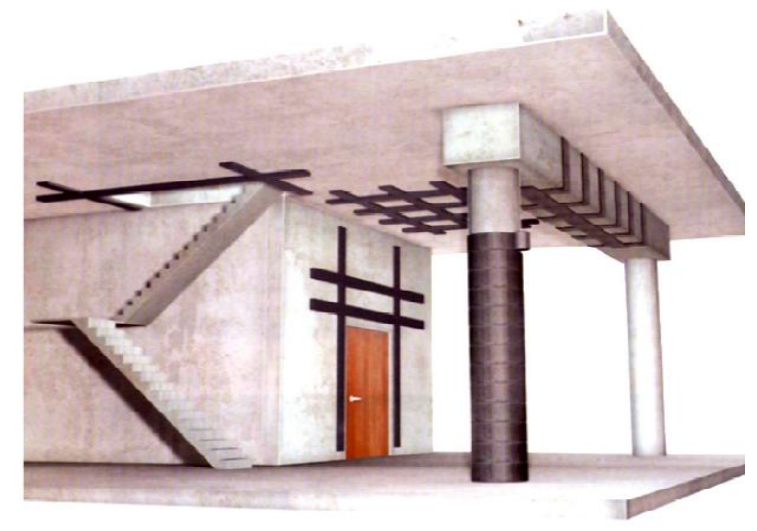

Figure (1): FRP applications.

\section{PREVIOUS RESEARCHES ON STRENGTHENED BEAM}

Reference [5] carried out an experimental and numerical analysis on fourteen beam specimens to study the flexural behaviour of prestressed concrete beams strengthened with externally bonded (GFRP) Laminates. Figure (2) shows Details of specimens' cross section and reinforcement.
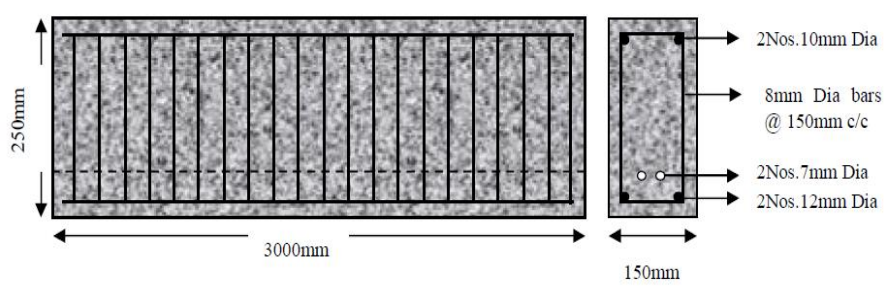

Figure (2): reinforcement detail of beam specimens [5].

The first group (T-series) included seven specimens casted with M 35 Grade concrete (one of them without strengthening, two strengthened with Uni-Directional Cloth (UDC) $3 \mathrm{~mm}$, and $5 \mathrm{~mm}$ thickness, two strengthened with Chopped Strand Mat (CSM) 3mm, and 5mm thickness, two strengthened with Woven Roving Cloth (WR) 3mm, and $5 \mathrm{~mm}$ thickness. The second group was the same specimens of the first group but casted with M 60 Grade concrete. Results showed that GFRP laminates enhanced the flexural 
strength $93.15 \%$ with UDC GFRP laminate, $57.24 \%$ with WR GFRP, and $24.70 \%$ with CSMGFRP, and $93.15 \%$ with UDCGFRP laminate for the first group and 54.18\% with UDCGFRP, $24.26 \%$ with WRGFRP and $16.74 \%$ with CSM GFRP for the second group. Figure (3 and 4) shows the effect of strengthening on strengthened beam specimens.

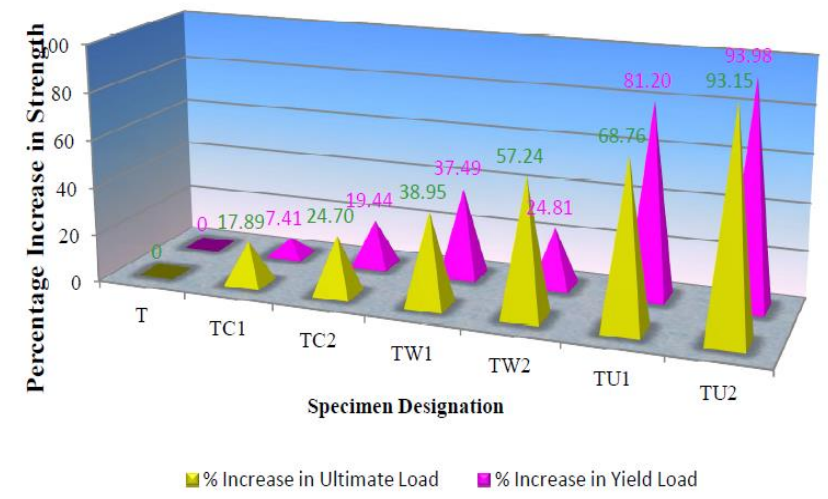

Figure (3): Effect of GFRP on strengthened T-beams [5].

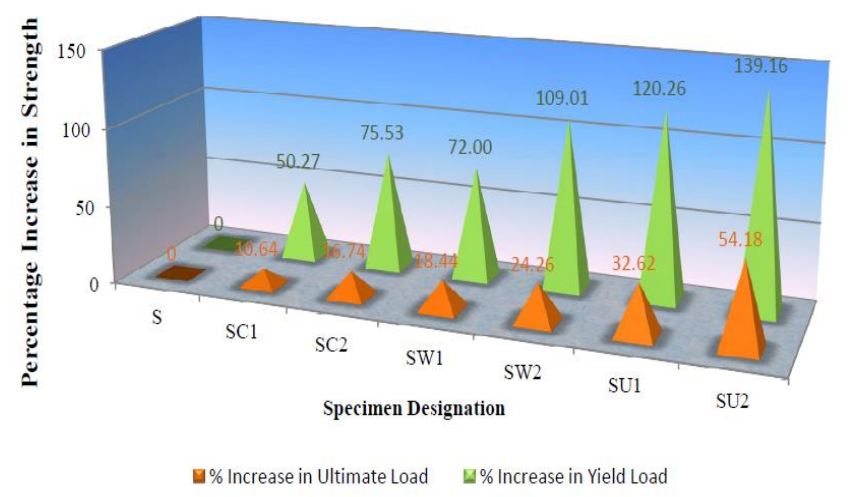

Figure (4): Effect of GFRP on strengthened S-beams [5].

Reference [7] conducted an experimental study to investigate the flexural behavior of RC beams strengthened with different CFRP laminates placed on the soffit of the beams. Figure (5) shows details of specimens' cross section and reinforcement. The specimens were one control beam (CB) without strengthening, three beams strengthened with 1 layer $1500 \mathrm{~mm}$ length, 2 layers (first $1500 \mathrm{~mm}$ length ,second 1300mm length) , 3 layer (first $1500 \mathrm{~mm}$ length ,second $1300 \mathrm{~mm}$ length, third $1100 \mathrm{~mm}$ length ) of CFRP Laminates, the last was strengthened with 1 layer CFRP laminate with U-shaped edge strips as shown at Figure (6). Results showed that increasing the number of layers; increase the flexural strength and stiffness of beam specimens. Using of U-shaped edge strips increased the flexure strength and delay the debonding of laminates till the final failure. Figure (7 and 8) shows the effect of increasing of number of layers and using U-shaped strips on the load deflection behaviour of beam specimens.

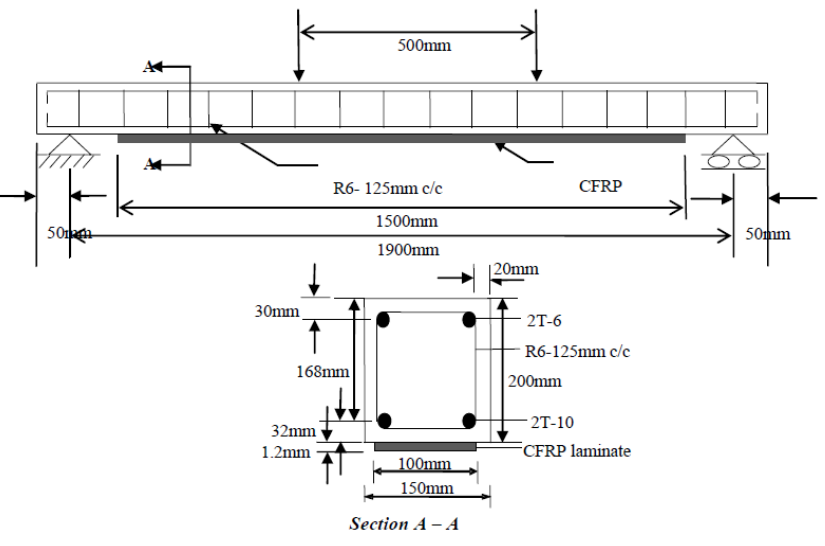

Figure (5): Detailing of beam specimens [7].

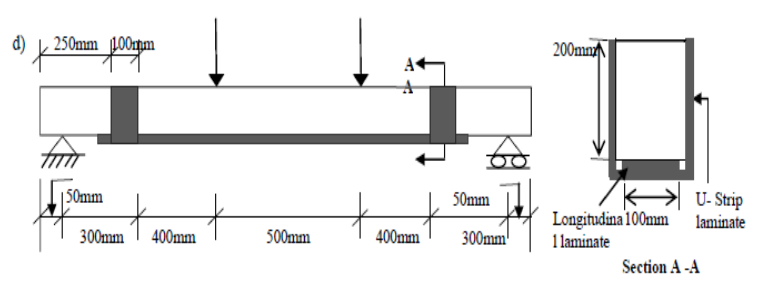

Figure (6): Detailing of u-shaped edge strips [7].

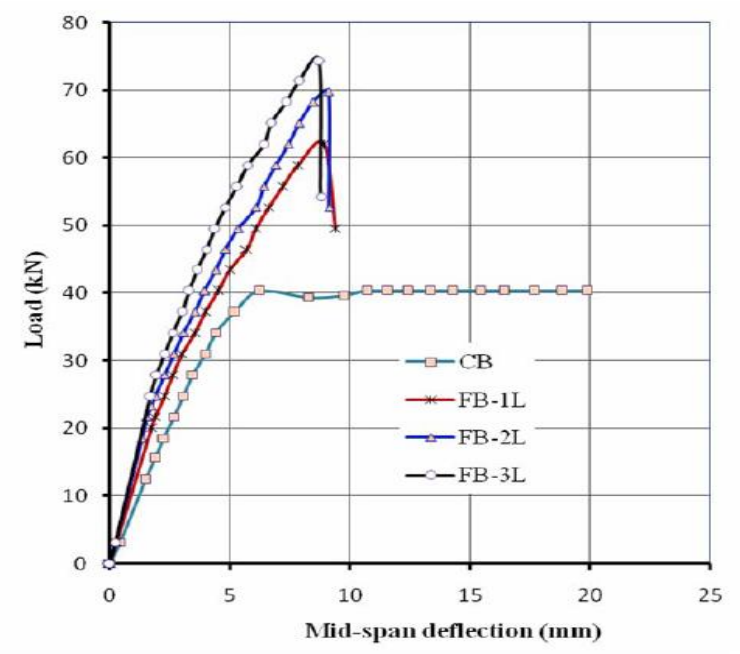

Figure (7): Effect of increasing No. of layers [7].

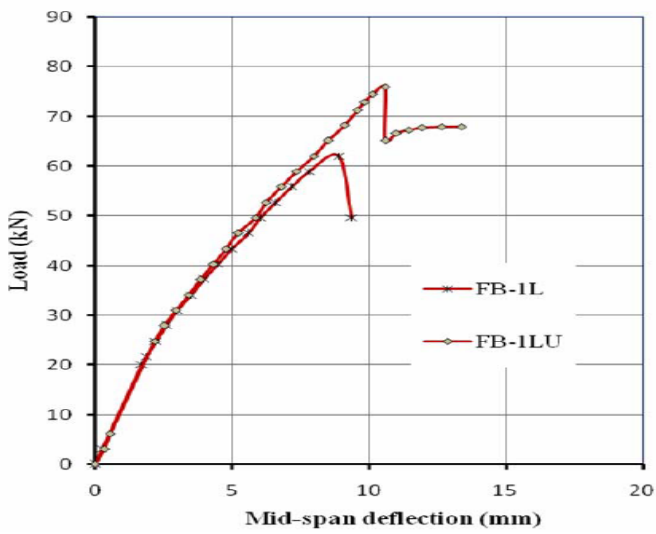

Figure (8): Effect of using u-shaped strips [7].

Reference [8] carried out an experimental study on reinforced concrete $(\mathrm{RC})$ beams strengthened with external flexural and Flexural-shear carbon fibre reinforced 
polymer (CFRP) and glass fibre reinforced polymer (GFRP). Fourteen specimens were casted and divided into two groups: first one beams flexural strengthened, the second beams flexural-shear strengthened. Detailing of the two groups shown on Figures $(9,11)$ and tables $(1,2)$. Results showed that the flexural-shear strengthening more effective than the flexural one in enhancing the ultimate load carrying capacity, stiffness ( CR5 , SR5). For CFRP flexural strengthened specimens the ultimate load carrying capacity increased between $41 \%$ and $125 \%$ than control specimen, also control development of cracks. Results for specimens shows at Figures $(10,12)$.

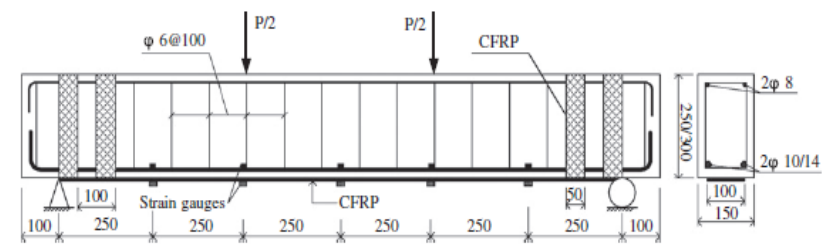

Figure (9) Detaing of flexural strengthened beams [8].

Table (1): properties of flexural strengthened beams [8].

\begin{tabular}{|c|c|c|c|c|c|c|c|}
\hline Beam & $h(\mathrm{~mm})$ & Concrete cover (mm) & Tensile reinforcement & Reinforcement ratio $(\%)$ & Shear span ratio & Recrack width (mm) & CFRP provided \\
\hline CR1 & 250 & 25 & 2610 & 0.49 & 233 & - & None (control \\
\hline $\mathrm{CR} 2$ & 250 & 25 & $2 \phi 10$ & 0.49 & 233 & - & CFRP shets"s \\
\hline $\mathrm{CR3}$ & 250 & 25 & $2 \phi 10$ & 0.49 & 233 & - & CFRP sheets $^{\text {b }}$ \\
\hline $\mathrm{CR} 4$ & 250 & 25 & 2410 & 0.49 & 233 & 051 & CFRP sheets ${ }^{b}$ \\
\hline CRS & 250 & 25 & 2014 & 0.95 & 233 & 059 & CFRP sheets ${ }^{b}$ \\
\hline CR6 & 300 & 25 & $2 \phi 10$ & 0.40 & 1.89 & 0.56 & CRRP sheets ${ }^{b}$ \\
\hline $\mathrm{CR} 7$ & 250 & 35 & $2 \$ 10$ & 0.51 & 2.44 & 0.53 & CFRP sheets ${ }^{b}$ \\
\hline
\end{tabular}

CFRP sheets (1500 × $100 \times 0.111 \mathrm{~mm})$ applied in one lajer.

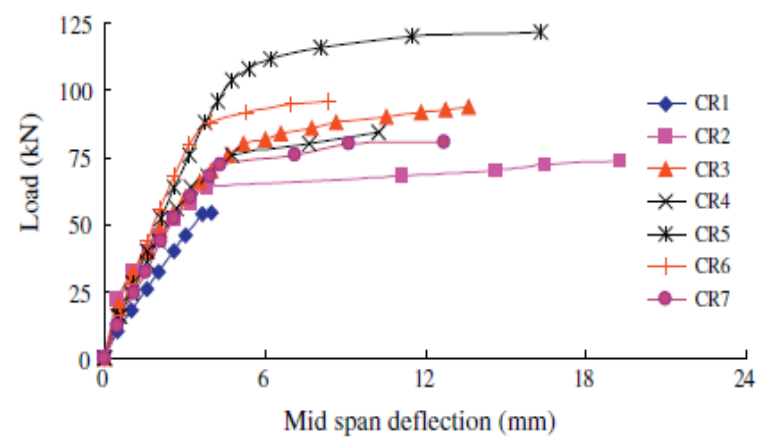

Figure (10): Load-deflection curves of flexural strengthened beams [8].

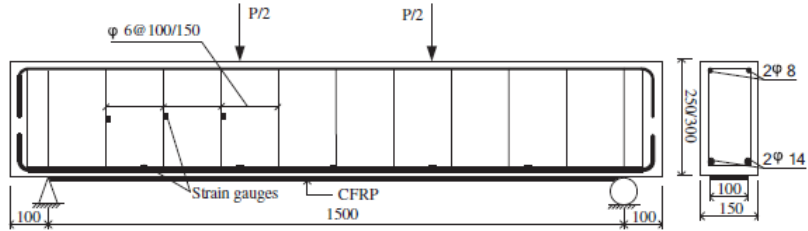

(a) Details of reinforcement

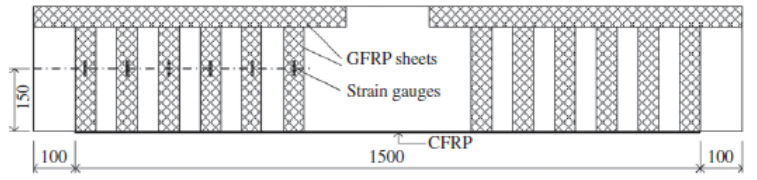

(b) U shape arrangement.

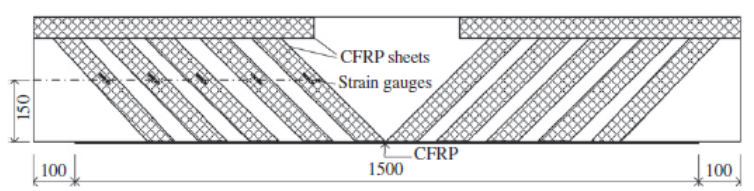

(c) L shape arrangement.

Figure (11) : Details of Flexural-Shear strengthening [8].

Table (2): Properties of flexural-shear strengthened

\begin{tabular}{|c|c|c|c|c|c|c|}
\hline Beam & $\mathrm{h}(\mathrm{mm})$ & Concrete strenghth & Stirups web & Stirrups atio $\left(y^{2}\right)$ & Shear span ratio & FRP provided \\
\hline SR1 & 300 & 200 & $\$ 60150$ & 0.25 & 1.89 & None (control) \\
\hline SR2 & 300 & $c 20$ & $\$ 60150$ & 0.25 & 1.89 & GFRP sheers" \\
\hline SFB & 300 & 200 & $\$ 60150$ & 0.25 & 1.89 & CFRP sheets $^{b}$ \\
\hline SR4 & 300 & $c 20$ & $\$ 60100$ & 0.38 & 1.89 & CFRP sheets $^{b}$ \\
\hline SPS & 250 & $C 20$ & $\$ 60150$ & 0.25 & 2.33 & CFRP sheets ${ }^{6}$ \\
\hline SA6 & 300 & 30 & $\$ 6150$ & 0.25 & 1.89 & None (control) \\
\hline SRT & 300 & 30 & $\$ 60150$ & 0.25 & 1.80 & CFRP shets ${ }^{b}$ \\
\hline
\end{tabular}

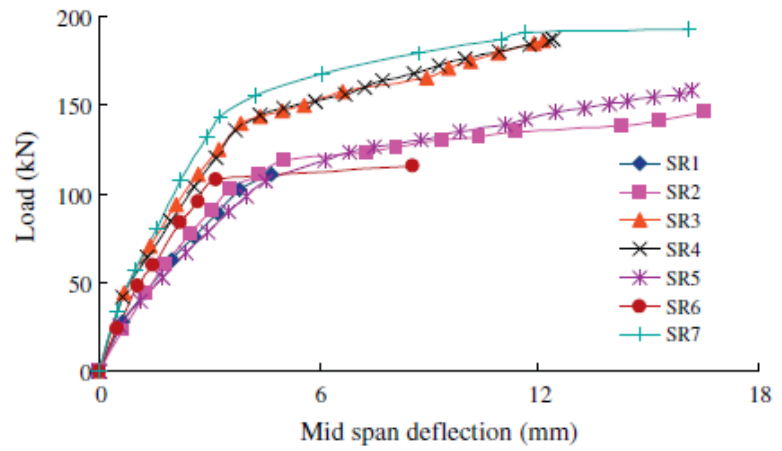

Figure (12) Load-deflection curve of flexural strengthened beams [8].

Reference [9] studied The Effect of Multiple Layers, Width, and Strength of FRP Sheets on Strength and Ductility of Strengthened Reinforced Concrete Beams in Flexure. Eleven specimens were casted with the same dimenssions and reinforcement details: one of them without strengthening considred at control beam, four strengthened with $5^{\prime \prime}$ width five layers of different types of frp (2 FRP-1, 2 FRP-2 ), also four strengthened with 1" width five layers of different types of FRP (2 FRP-1, 2 FRP-2 ) and three other strengthened with $5^{\prime \prime}$ width one layerof different types of frp (2 FRP-1, 1 FCV Plates). Details of specimens dimenssion and reinforcement shown in Figure (13), properties of Results Showed that Beams strengthened with 5 " width one layer of FRP increasing load carrying capacity from $23.6 \%$ to $47.2 \%$ according to type of FRP and doesn't have significant effect on ductility. Beams 
strengthened with $5 "$ width five layers enhancing load carrying capacity from $54 \%$ to $66 \%$ according to type of FRP but reduce the ductility. Using five layers of FRP with narrow width (1" ) have no effect on the strength of the specimens.Ultimate load capacity and failure mode of strengthened beams shown at table (3).

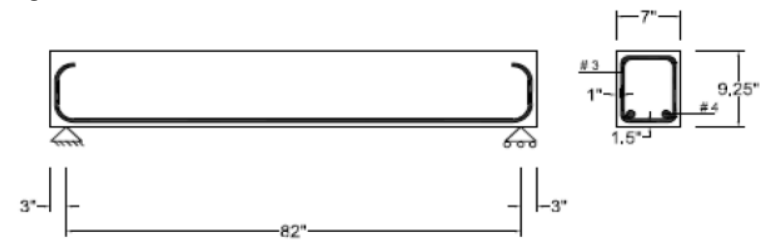

Figure (13): Detaing of beam specimens [9].

Table (3): Ultimate load capacity and failure mode of strengthened beams [9].

\begin{tabular}{|c|c|c|c|c|c|c|}
\hline Beam & \begin{tabular}{|l|} 
FRP \\
Type
\end{tabular} & \begin{tabular}{|l|} 
FRP \\
Width \\
\end{tabular} & $\begin{array}{l}\text { No. of } \\
\text { Layers }\end{array}$ & Failure Mode & $\begin{array}{l}\text { Ultimate } \\
\text { Load (lbs.) }\end{array}$ & $\begin{array}{l}\text { Load } \\
\text { Increase }\end{array}$ \\
\hline 1 & Non & N.A. & N.A. & Yielding of steel reinforcing bars & 19300 & N.A. \\
\hline 2 & FRP-1 & 5 & 5 & Shear failure at FRP end & 32050 & $66 \%$ \\
\hline 3 & FRP-1 & $1 "$ & 5 & FRP debonding & 18986 & $-1.6 \%$ \\
\hline 4 & FRP-2 & $1 "$ & 5 & FRP debonding & 19394 & $0.5 \%$ \\
\hline 5 & FRP-2 & $5 \%$ & 5 & Shear failure at FRP end & 29869 & $54 \%$ \\
\hline 6 & FRP-1 & $1 "$ & 5 & FRP debonding & 19937 & $3.3 \%$ \\
\hline 7 & FRP-1 & 5 & 5 & Shear failure at FRP end & 31779 & $64 \%$ \\
\hline 8 & FRP-1 & 5 & 1 & FRP rupture & 26290 & $36.2 \%$ \\
\hline 9 & FRP-1 & $5 "$ & 1 & FRP rupture & 23862 & $23.6 \%$ \\
\hline 10 & FCV & 5 & 1 & Shear failure at FRP end & 28413 & $47.2 \%$ \\
\hline 11 & FRP-2 & 5 & 5 & Shear failure at FRP end & 29960 & $55.2 \%$ \\
\hline
\end{tabular}

Reference [10] conducted an experimental study to investigate the flexural behaviour of Un-Bonded PostTensioned concrete beams (UBPT) strengthened with Glass Fibre Reinforced Polymer (GFRP) plates. Five specimens were casted with dimensions of $(150 \mathrm{~mm}$ wide, $250 \mathrm{~mm}$ height and $3000 \mathrm{~mm}$ length). One considered as control beam, two strengthened with Chopped Strand Mat (CSM) (GFRP) with thickness (3mm,5mm) and named as (UBPTC3,UBPTC5 respectively), the last two strengthened with Uni-directional Cloth (UDC) (GFRP) with thickness $(3 \mathrm{~mm}, 5 \mathrm{~mm})$ and named as (UBPTU3, UBPTU5) respectively. The results showed that using GFRP for strengthened beams enhancing the load carrying capacity as shown in Figure (14) and table (4).

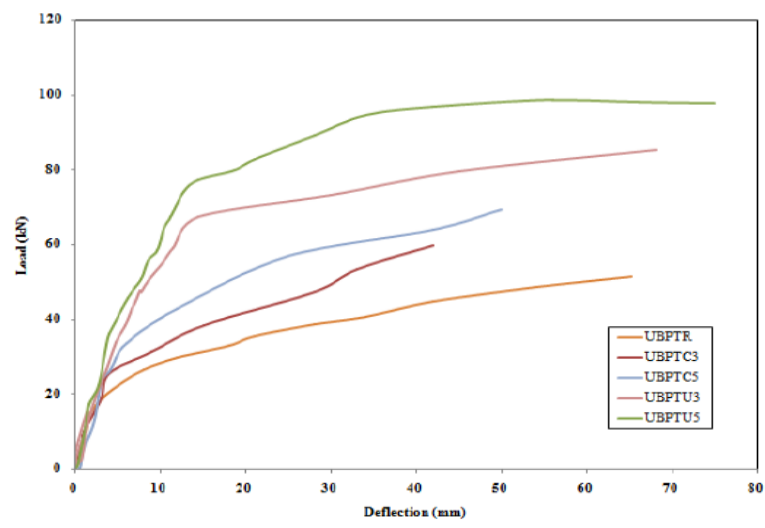

Figure (14): P- Delta curve of strengthened beams [10].
Table (4): ultimate and cracking load for strengthened beams [10].

\begin{tabular}{|c|c|c|c|c|}
\hline Beam Specimens & $\begin{array}{c}\text { Yield Load } \\
(\mathbf{k N})\end{array}$ & Ultimate Load $(\mathbf{k N})$ & $\begin{array}{c}\text { Deflection at Ultimate Load } \\
(\mathbf{m m})\end{array}$ & Ductility Index \\
\hline UBPTR & 18.6 & 51.5 & 65.2 & 21 \\
\hline UBPTC3 & 20.4 & 59.5 & 42.0 & 14 \\
\hline UBPTC5 & 23.2 & 69.4 & 50.0 & 16 \\
\hline UBPTU3 & 33.7 & 85.2 & 68.0 & 14 \\
\hline UBPTU5 & 36.1 & 97.5 & 75.5 & 19 \\
\hline
\end{tabular}

Reference [11] studied the flexural behavior of ten reinforced concrete beam strengthened with CFRP fabrics under static and cyclic loading up to failure. Results showed the strengthening enhancing the ultimate load capacity from $18 \%$ to $20 \%$ for single layer, $40 \%$ to $50 \%$ for two layers for cyclic and static load. Reference [12] carried out an experimental study to the behavior of beams strengthened with glass fiber reinforced polymer (GFRP) laminates. Nine beam specimens with dimensions of $(150 * 150 * 100 \mathrm{~mm})$ were casted and tested under fourpointed loading until failure. The nine beam specimens divided into three beams without strengthening considered as control beams, two beams strengthened with GFRP Wrap in the bottom (flexure only), two strengthened with u-wrap GFRP in both flexure and shear, two strengthened with u-wrapped GFRP in shear zone only. Results showed that using GFRP at only the soffit of the beam enhance the strength by $23 \%$ over the control beam, using u-wrapped GFRP in both flexure and shear enhance the strength by $41 \%$. Figure (15) shows the effect of strengthening on load deflection behavior of strengthened beams.

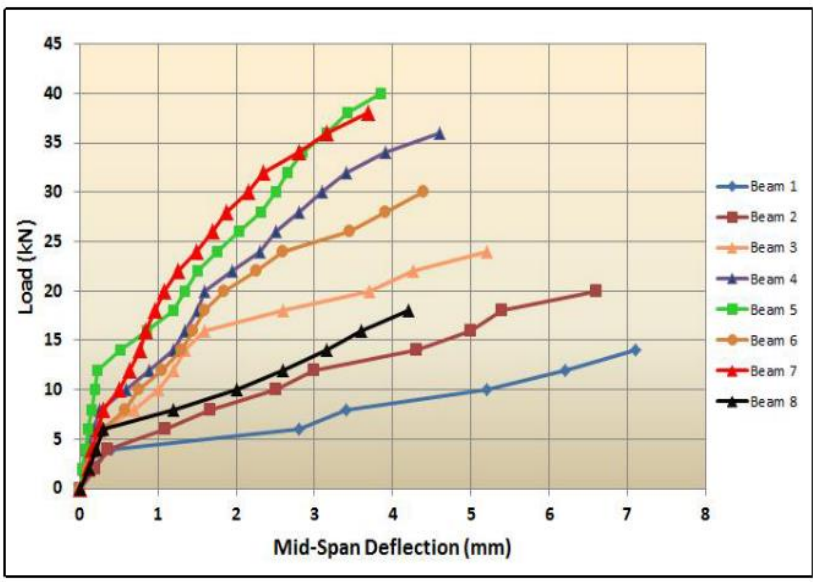

Figure (15): Load deflection curve for all specimens [12].

Reference [13] studied the flexural behavior of reinforced concrete beams strengthened with externally bonded steel plates. Reference [14] presented an experimental investigation into strengthening of reinforced concrete beams by external steel plate using bonded and unbonded connectors. Reference [15] carried out an experimental study to investigate the efficiency of using fasting steel bolts in bonding FRP laminates to reinforced concrete beams. Five beam specimens with full scale and dimensions of $(150 * 300 * 2400 \mathrm{~mm})$ were casted and tested under static -pointed loading up to failure as shown in figure (16). B1 with no strengthening. B2 strengthened with CFRP 
laminates of width $50 \mathrm{~mm}$ and externally bonded to the bottom of the beam using epoxy resin only. B3 strengthened with CFRP laminates and bonded using epoxy in addition to two bolts on each side of the beam, the bolts was $10 \mathrm{~mm}$ diameter and $200 \mathrm{~mm}$ spacing between the two bolts. B4 strengthened with CFRP laminates and bonded using epoxy in addition to 10 rivets at spacing 20 cm.B5 strengthened with CFRP laminates at the bottom of the specimen and three CFRP laminate of $5 \mathrm{~mm}$ width on the beam both sides and both ends ( 3 U-wrapping CFRP ). The results showed that using bonding technique by fastened bolts, which enhance the flexure strength by $23 \%$. It is not recommended to use partially fastening by bolts at beam end only.

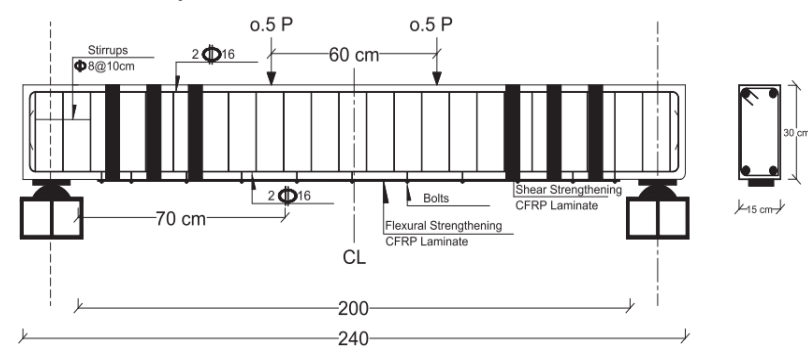

Figure (16): Longitudinal and cross section details of experimental beams [15].

Reference [16] conducted an experimental study to inspect the flexural behavior of reinforced concrete (RC) beams strengthened through the combined externally bonded and near-surface mounted (CEBNSM) technique. Six beams with dimensions $(125 * 250 * 3300 \mathrm{~mm})$ were casted and tested under four-pointed loading up to failure. Results showed that strengthened beams enhanced the behavior of the ultimate load carrying capacity, stiffness, cracking, and strain compatibility where, the ultimate capacity of the CEBNSM strengthened beams increased from $71 \%$ to $105 \%$ compared to that of the control beam. Table (5) shows the experimental test results.

Table (5): Summery of experimental test results [16].

\begin{tabular}{cccccccc}
\hline Beam ID & $P_{\mathrm{cr}}(\mathbf{k N})$ & $\Delta_{\mathrm{cr}}(\mathrm{mm})$ & $P_{\mathrm{y}}(\mathbf{k N})$ & $\Delta_{\mathbf{y}}(\mathrm{mm})$ & $P_{\mathrm{u}}(\mathbf{k N})$ & $\Delta_{\mathrm{u}}(\mathrm{mm})$ & Failure modes \\
\hline CB & 5 & 0.5 & 36 & 15.0 & 39 & 34.3 & FFC \\
CBC8P1 & 11 & 1.5 & 50 & 14.9 & 71 & 39.7 & FFF \\
CBC8P2 & 13 & 1.9 & 55 & 15.2 & 77 & 31.3 & FFF \\
CBC10P1 & 13 & 1.6 & 54 & 16.6 & 82 & 43.3 & FFF \\
CBC10P2 & 15 & 2.3 & 69 & 23.7 & 87 & 42.7 & CFD \\
CBC10P2A & 16 & 2.8 & 80 & 24.7 & 105 & 47.9 & FFC \\
\hline
\end{tabular}

$P_{\text {cr }}=$ first crack load; $P_{y}=$ yield load; $P_{\mathrm{u}}=$ ultimate load; $\Delta_{\mathrm{cr}}=$ deflection at 1 st crack; $\Delta_{\mathrm{y}}=$ deflection at yield of steel; $\Delta_{\mathrm{u}}=$ mid-span deflection at failure load; $\mathrm{FFC}=$ flexural failure (concrete crushing after steel yielding
$\mathrm{FFF}=$ flexure failure due to FRP rupture; $\mathrm{CFD}=\mathrm{CFRP}$ fabric delamination.

\section{CONCLUSIONS}

In this paper presents a review of current and relevant studies on strengthening of reinforced and pre-stressed concrete beams using EB FRP techniques. The following conclusions can obtained from the current study:

1. Multiple layers of FRP wide sheets can contribute to additional strength of the beam, but will reduce the ductility of beams but using multiple layers of FRP narrow strips does not add to the strength of the beam.
2. Using transverse edge strip (u-wrap) had a good effect on improvement flexural strength and the debonding of laminates occurred just before the final failure. Nevertheless, the possible brittle failure of the strengthened beams still needs to be considered.

3. The bonding technique using rivets fastened through FRP laminate and concrete is very efficient technique for full contact for FRP laminate. Nevertheless, the specimen that fastened the FRP laminate by two rivets only on both beam ends enhance the flexural capacity by only $5 \%$ over the beam strengthened and bonded by epoxy only. So, it is not recommended to use partially fastening by rivets at beam end only.

\section{REFERENCES}

[1] ACI Committee 318 (2014) Building Code Requirements for Structural Concrete (ACI 318-14), American Concrete Institute.

[2] ACI 440.2R-08 (2008) Guide for the design and construction of externally bonded FRP systems for strengthening existing structures, ACI committee 440.

[3] Soror, A. Y., Heiza, K. M. and Tayel. M. A. (2018) 'State of the art review: Flexural Strengthening of reinforced and pre-stressed concrete beams using Fiber reinforced polymers' second international conference, faculty of engineering, menoufia university.

[4] Günaslan, S. E., Karaşin, A. and Öncü, M. E. (2014) 'Properties of FRP Materials for Strengthening', IJISET - International Journal of Innovative Science, Engineering \& Technology, 1(9), pp. 656-660.

[5] Vijayan, D. S. and Revathy, J. (2016) 'Experimental Investigation on the Static Performance of GFRP Strengthened Prestressed Concrete Beams', World Applied Sciences Journal, 34(10), pp. 1366-1369.

[6] Soror, A. Y., Tayel. M. A. and Heiza, K. M (2018) 'Post Tensioned Reinforced Concrete Beams Strengthened with Near Surface Mounted Techniue' second international conference on INNOVATIVE BUILDING MATERIALS (IBMC18).

[7] Sobuz, H. R. et al. (2011) 'Structural strengthening of RC beams externally bonded with different CFRP laminates configurations', Journal of Civil Engineering (IEB), 39(1), pp. 33-47.

[8] Z. Guan. et al. (2011) "Structural behaviour of RC beams with external flexural and flexural-shear strengthening by FRP sheets :Composites: Part B 44 (2013) 604-612.

[9] Bsisu, K. A., Srgand, S. and Ball, R. (2015) 'The Effect of Width, Multiple Layers and Strength of FRP Sheets on Strength and Ductility of Strengthened Reinforced Concrete Beams in Flexure', Jordan Journal of Civil Engineering, 9(1), pp. 33-42.

[10] Revathy, J. and Sriraman, M. (2014) 'Structural Response of FRP Strengthened Post-Tensioned Concrete Beams', Research Journal of Recent Sciences, 3, pp. 198-202. 
[11] Revathy, J. and Sriraman, M. (2014) 'Structural Response of FRP Strengthened Post-Tensioned Concrete Beams', Research Journal of Recent Sciences, 3, pp. 198-202.

[12] Balamuralikrishnan, R. and Jeyasehar, C. A. (2009) 'Flexural Behavior of RC Beams Strengthened with Carbon Fiber Reinforced Polymer (CFRP) Fabrics', The Open Civil Engineering Journal, 3(1), pp. 102-109.

[13] Ozbek, B. E. (2016) 'Strengthening of RC Beams with Solid Steel Plates', Athens Journal of Technology \& Engineering, (December), pp. 291-298.

[14] Alkerwei, R. H. (2014) 'Strengthening of R.C. Beams by External Steel Plate Using Bonded and Unbonded Connectors', Eng. \&Tech.Journal, 3(1), pp. 90- 100.

[15] Louis, M. A. and Jarallah, H. K. (2013) 'LoadDeflection Behavior Of Reinforced Beams Strengthened With CFRP Sheets', Journal of Engineering and Development, 17(4), pp. 14-26.

[16] M. Technique, "Strengthening of RC Beams Using Externally Bonded Reinforcement Combined with Near-Surface," 2016.

[17] Kovačič, S., Žagar, E., \& Slugovc, C. (2019). Strength versus toughness of emulsion templated Poly ( Dicyclopentadiene ) foams. Polymer, 169 (November 2018), 58-65. 